\title{
Bonding and Integration of C-C Composite to Cu-Clad-Molybdenum for Thermal Management Applications
}

\author{
R. Asthana ${ }^{1}$, M. Singh ${ }^{2}$,and T.P. Shpargel ${ }^{3}$ \\ ${ }^{1}$ Department of Engineering and Technology \\ University of Wisconsin-Stout \\ Menomonie, WI 54751, USA \\ ${ }^{2}$ Ohio Aerospace Institute \\ NASA Glenn Research Center \\ Cleveland, OH 44135, USA \\ ${ }^{3}$ ASRC Aerospace \\ Cleveland, OH 44135, USA
}

\begin{abstract}
Two- and three-dimensional carbon-carbon composites with either resin-derived matrix or CVI matrix were joined to $\mathrm{Cu}$-clad-Mo using active $\mathrm{Ag}-\mathrm{Cu}$ braze alloys for thermal management applications. The joint microstructure and composition were examined using Field-Emission Scanning Electron Microscopy and Energy-Dispersive Spectroscopy, and the joint hardness was characterized using the Knoop microhardness testing. Observations on the infiltration of the composite with molten braze, dissolution of metal substrate, and solute segregation at the C-C surface have been discussed. The thermal response of the integrated assembly is also briefly discussed.
\end{abstract}

* Currently with ASRC Aerospace, Cleveland, $\mathrm{OH}$ 


\title{
Bonding and Integration of C-C Composites to Copper-Clad-Molybdenum for Thermal Management Applications
}

\author{
R. Asthana*, M. Singh ${ }^{\star *}$, and T.P. Shpargel ${ }^{\star * *}$ \\ * University of Wisconsin-Stout \\ Menomonie, WI 54751 \\ **Ohio Aerospace Institute \\ NASA Glenn Research Center \\ Cleveland, OH 44135 \\ *** ASRC Aerospace \\ NASA Glenn Research Center \\ Cleveland, OH 44135
}

\section{Overview}

- Introduction and Background

- Experimental Procedures

- Materials and Brazing

- Characterization (Microstructure, Microhardness)

- Results and Discussion

- Microstructure and Composition of Joints

- Microhardness

- Residual Stress and Thermal Considerations

- Concluding Remarks

- Acknowledgments 
National Aeronautics and Space Administration

\section{Thermal Properties of Some Typical Thermal Management Materials}

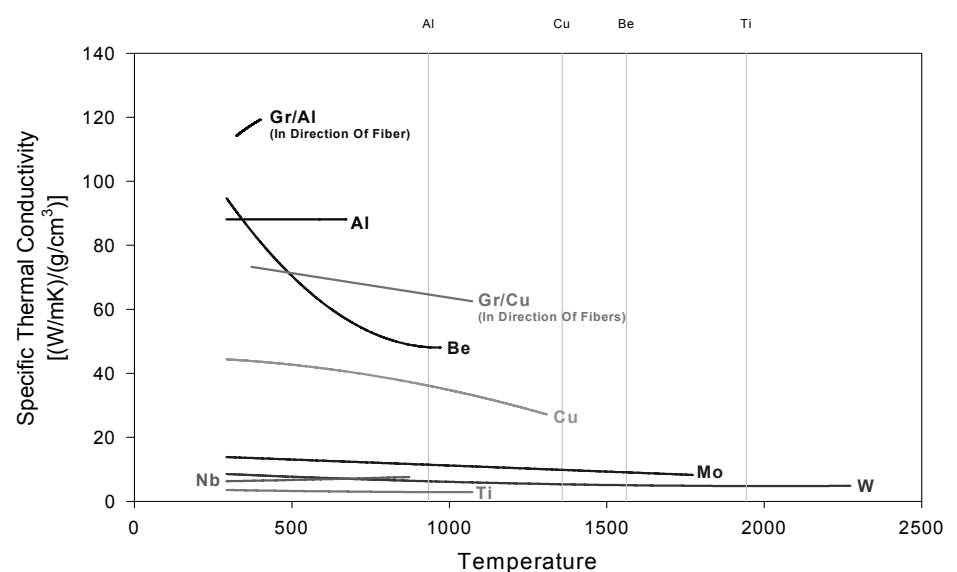

(K)

\section{Thermal Management Material Properties}

Carbon-Carbon Composites Provide Tremendous Advantage and Excellent Benefits for Thermal Management
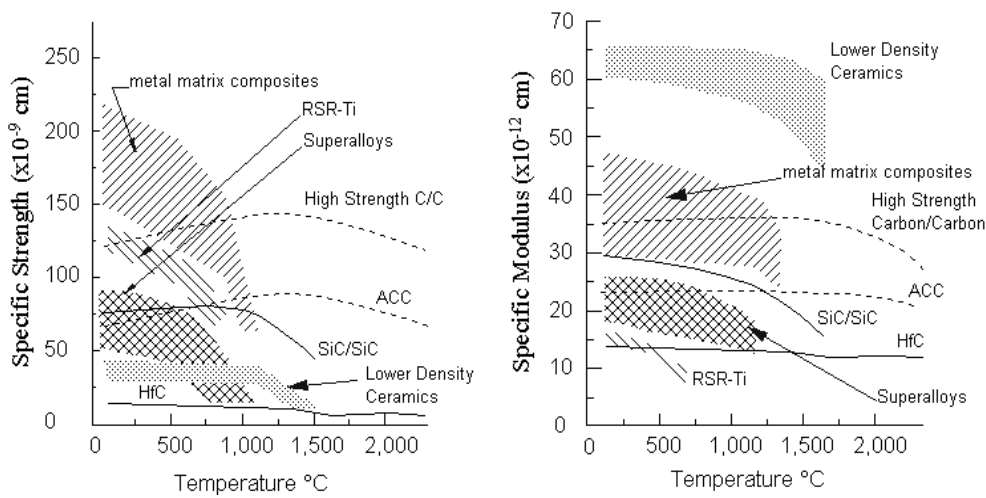

From: "High thermal conductivity composites for passive thermal management," Metal Matrix Composites Information Analysis Center -Current Highlights, 8, 2 (1988). 


\section{Application of Carbon-Carbon Composite Materials in Thermal Management Applications}

Thermal conductivity of $\mathrm{C} / \mathrm{C}$ composites strongly depends on the fiber type, architecture, and composite processing technology

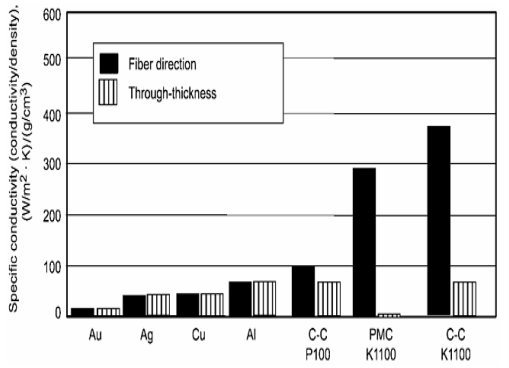

Source: K. Kearns, Composites, ASM Handbook, Vol. 21 (2002) 1067-1070.

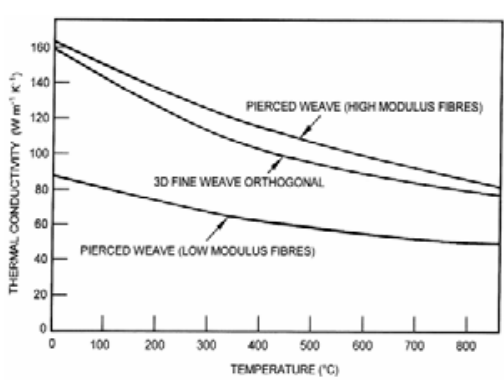

Source: Comprehensive Composite Materials, Vol. 4, 3 (2000)

- High modulus, high conductivity pitch based carbon fibers can be used to improve the thermal properties of $C-C$ composites.

\section{Active Metal Brazing of Titanium to $\mathrm{C} / \mathrm{C}$ Composites for Heat Rejection Systems}

- Recently, we had joined C-C composite to Ti tubes for lightweight heat exchanger applications.

- Both direct bonding using braze layers and indirect bonding using a porous carbon foam (saddle material) and braze layers were employed.

- Excellent bonding of active braze to foam, C-C Composite, and Ti Tube occurred.

- Failure always occurred in Poco HTC (Saddle Material) indicating that bond strength exceeded the fracture strength of foam.

1. M. Singh et al, Mater. Sci. Eng. A (in press).

2. M. Singh et al, Mater. Sci. Eng., A 412, 2005, 123-128.

3. G.N. Morscher et al, Mater. Sci. Eng., A 418(12), 2006, pp 19-24.

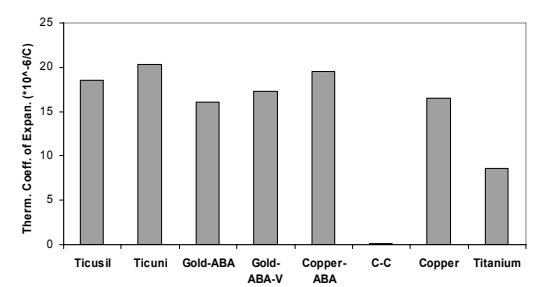

Large ditterence in CTE of C-C and metals lead to large residual stresses

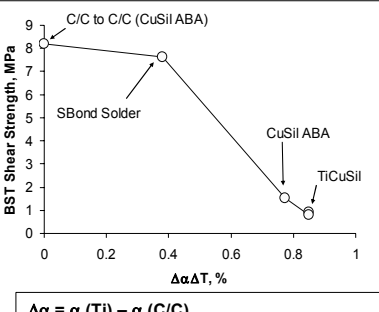
$-\alpha(\mathrm{C} / \mathrm{C})$ $\Delta T=T$ (liquidus $\sim$ processing) $-25^{\circ} \mathrm{C}$ 


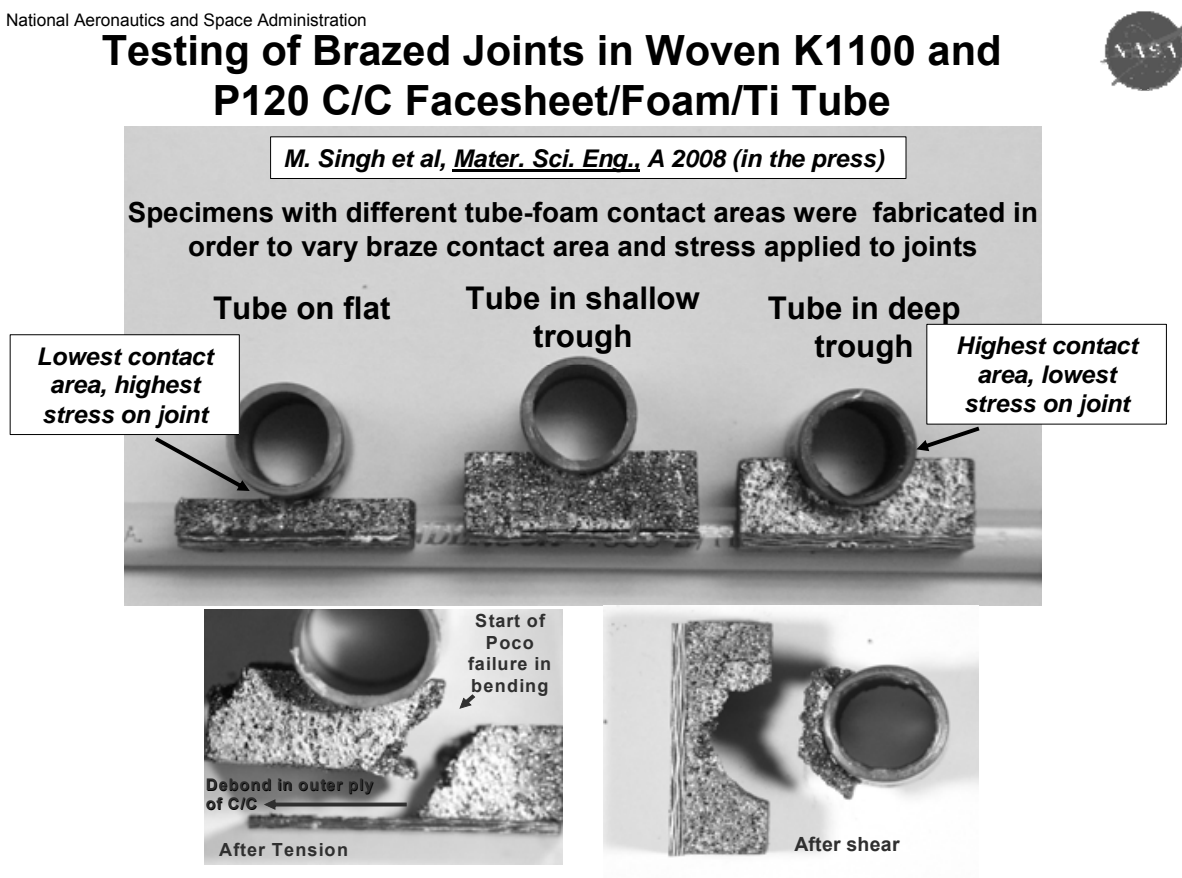

www.nasa.gov

National Aeronautics and Space Administration

Why Copper Clad Molybdenum was chosen as a Thermal Management Material ?
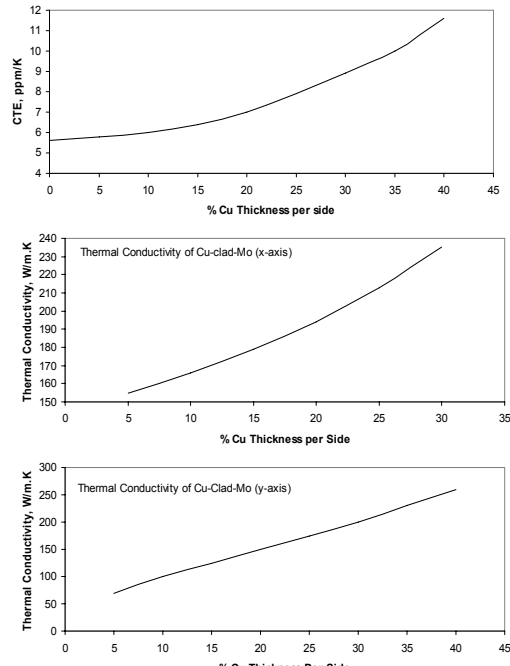

(from Electronic Materials and Processes Handbook, C.A. Harper, McGraw-Hill, 2003)
- Copper has excellent thermal conductivity (K for OFHC Cu: 401 W/m.K).

- CTE of $\mathrm{Cu}$ is high (16.5 ppm/K). Difficulty in joining to ceramic substrates.

- Low annealing temperature of $\mathrm{Cu}$ causes softening at moderate heat input.

- Cladding Mo with Cu lowers CTE and promotes thermoelastic compatibility with ceramics.

- Some loss of thermal conductivity (Mo: 138 W/m.K, Cu: 401 W/m.K).

- Small weight penalty (density of $\mathrm{Cu}: 8,900 \mathrm{~kg} \cdot \mathrm{m}^{-3}$, density of Mo: $10,280 \mathrm{~kg} \cdot \mathrm{m}^{-3}$ ). 


\section{Objective}

- Develop brazing approaches for 2D and 3D C-C composites with resin and CVI matrices to $\mathrm{Cu}$-cladMo using active braze alloys.

- Characterize the joint microstructure, composition, and microhardness behavior.

\section{Experimental Procedure: Materials and Properties}

- 2-D and 3-D C-C composites (Resin +CVI Carbon matrix) Goodrich Corp., CA.

- C-C composites (Resin derived matrix) - C-CAT, Inc., TX.

- Cu-clad-Mo plates (Cu-Mo-Cu ratio: 13\%-74\%-13\%) H.C. Starck, Inc., MA.

- Active braze alloy (ABA) powders - Morgan Advanced Ceramics, CA.

\section{Composition and Properties of Brazes}

\begin{tabular}{|c|c|c|c|c|c|c|c|c|}
\hline Braze (composition, \%) & $\begin{array}{c}\mathbf{T}_{\text {L, }}, \\
{ }^{\circ} \mathbf{C}\end{array}$ & $\begin{array}{c}\mathbf{T}_{\mathbf{S}}, \\
{ }^{\circ} \mathbf{C}\end{array}$ & $\begin{array}{c}\mathbf{E}, \\
\mathbf{G P a}\end{array}$ & $\begin{array}{c}\mathbf{Y S}, \\
\mathbf{M P a}\end{array}$ & $\begin{array}{c}\text { UTS, } \\
\mathbf{M P a}\end{array}$ & $\begin{array}{c}\mathbf{C T E}, \\
\times 10^{-6} \mathbf{C}^{-1}\end{array}$ & $\begin{array}{c}\text { \% } \\
\mathbf{E I} .\end{array}$ & $\begin{array}{c}\mathbf{K}, \\
\mathbf{W} / \mathbf{m} . \mathbf{K}\end{array}$ \\
\hline $\begin{array}{c}\text { Cusil-ABA } \\
(63 \mathrm{Ag}-35.3 \mathrm{Cu}-1.75 \mathrm{Ti})\end{array}$ & 815 & 780 & 83 & 271 & 346 & 18.5 & 42 & 180 \\
\hline $\begin{array}{c}\text { Ticusil } \\
(68.8 \mathrm{Ag}-26.7 \mathrm{Cu}-4.5 \mathrm{Ti})\end{array}$ & 900 & 780 & 85 & 292 & 339 & 18.5 & 28 & 219 \\
\hline
\end{tabular}

E: Young's modulus, YS: yield strength, UTS: tensile strength, CTE: coefficient of thermal expansion, \%El: percent elongation, K: thermal conductivity 


\section{Experimental Procedure}

- Substrates cut into $2.54 \mathrm{~cm} \times 1.25 \mathrm{~cm} \times 0.25 \mathrm{~cm}$ plates and ultrasonically cleaned in acetone for $15 \mathrm{~min}$.

- Braze powders mixed with glycerin to dough-like consistency and braze paste manually applied to $C-C$ surface.

- Assembly heated under vacuum ( 10-6 torr) to $15-20^{\circ} \mathrm{C}$ above braze $\mathrm{T}_{\mathrm{L}}$. After $5 \mathrm{~min}$. soak, slowly cooled ( $\sim 5^{\circ} \mathrm{C}$ per min.).

- Brazed joints mounted in epoxy, ground, polished, and examined using optical microscopy and Field Emission Scanning Electron Microscopy (Hitachi 4700) coupled with EDS.

- Microhardness (Knoop indenter) on Struers Duramin-A300 machine (200 g load, $10 \mathrm{~s}$ ). Four-to-six scans across each joint.

\section{C-C Composite/Cu-Clad-Mo Joints for Thermal Management Applications}

- Resin-derived C-C
composites brazed to Cu-
clad Mo using active braze
alloys (ABA).
- Good metallurgical bonding
at joints, with some
dissolution, diffusion, and
solute redistribution.
- Ti segregated at C-C surface.
Cu-ABA joints displayed the
largest Ti concentrations at
joint.
- Microhardness gradients
exist at joints.
- C-C/Cu-clad Mo systems may
have potential for thermal
management applications.
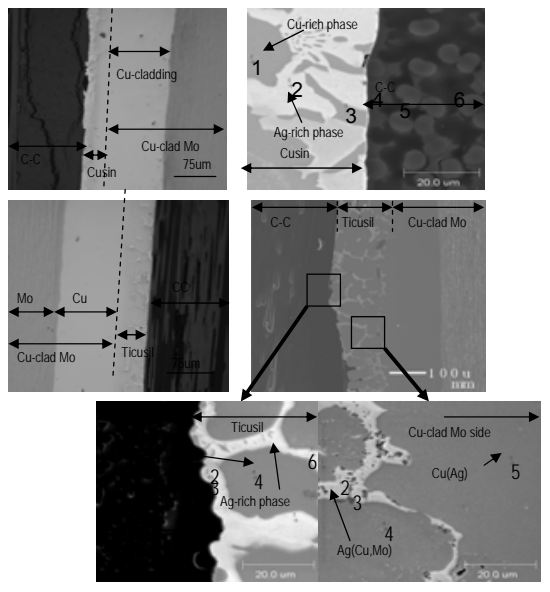
3-D C-C Composite/Cu-clad-Mo Joint
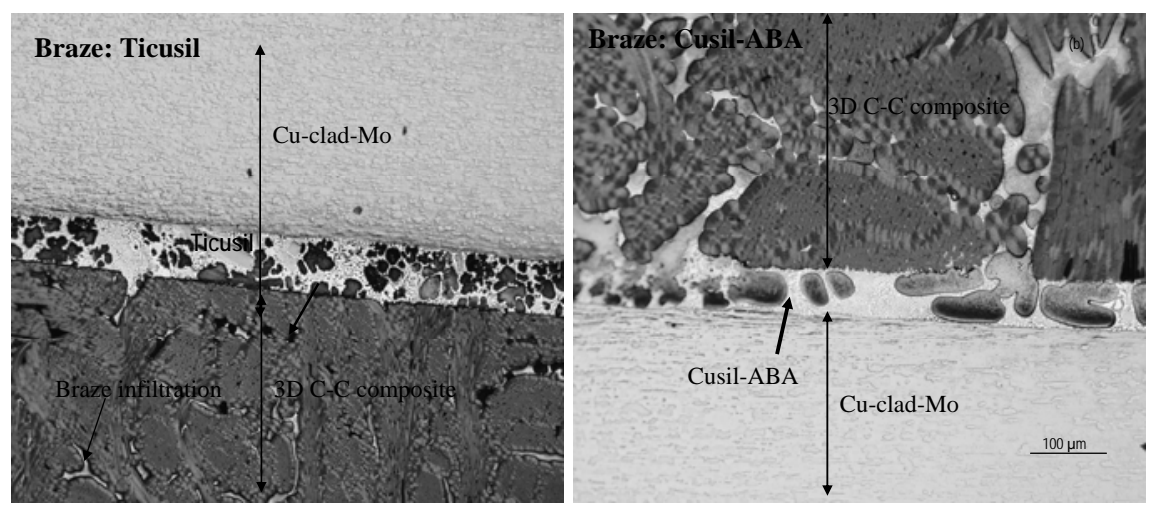

- Braze penetration to several hundred micrometers in $\mathbf{5}$ min

- No effect of fiber ply orientation on infiltration.

- Improved wetting by $\mathrm{Ti}$ in braze facilitated infiltration.

- No reaction choking and flow cessation from carbide forming reactions.

- Extensive infiltration of C-C consistent with sessile-drop tests

(complete disappearance of drops in porous carbon!).

\section{3-D C-C composite/Cusil ABA/Cu-clad-Mo joint}
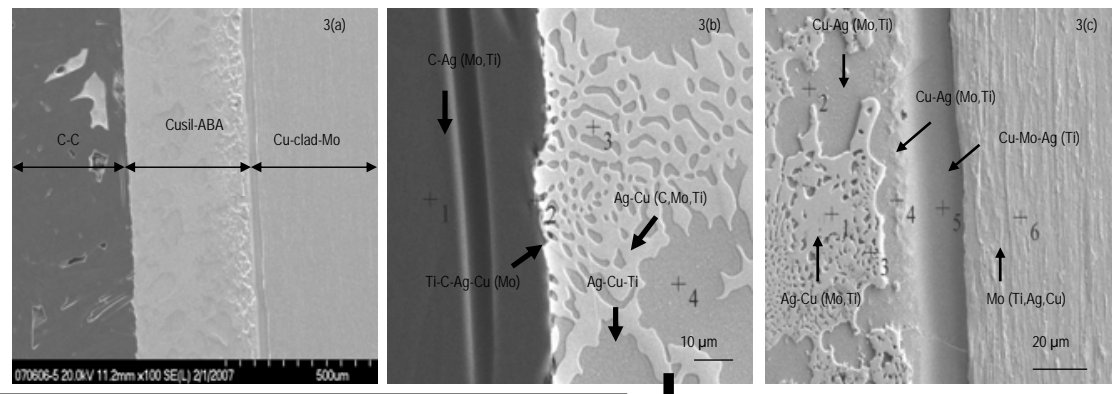

- High concentrations of $\mathrm{Ti}$ at interface.

- Two-phase eutectic structure in braze (Ag-rich lightgrey and Cu-rich dark grey).

- No melting of clad layer (M.P. of Cu: $1086^{\circ} \mathrm{C}$ )

- Possible formation of titaium carbide $(\mathrm{Ti}+\mathrm{C} \rightarrow \mathrm{TiC}$, $\Delta \mathrm{G}=-171.18 \mathrm{~kJ}$ at $\left.850^{\circ} \mathrm{C}\right)$.

- Sub-stoichiometric carbides (TiC0.95, TiC0.91, TiC0.80, TiC0.70, TiC0.60 and TiC0.48) may also form.

\begin{tabular}{|c|c|c|c|c|c|}
\hline Location & $\mathrm{C}$ & $\mathrm{Ti}$ & $\mathrm{Cu}$ & $\mathrm{Mo}$ & $\mathrm{Ag}$ \\
\hline Point 1 & 96.468 & 0.693 & 0.000 & 0.723 & 2.116 \\
\hline Point 2 & 35.131 & 49.912 & 5.203 & 0.941 & 8.813 \\
\hline Point 3 & 0.675 & 0.328 & 3.881 & 0.281 & 94.835 \\
\hline Point 4 & 0.000 & 2.437 & 89.469 & 0.000 & 8.094 \\
\hline
\end{tabular}




\section{3-D C-C composite/Ticusil/Cu-clad-Mo joint}

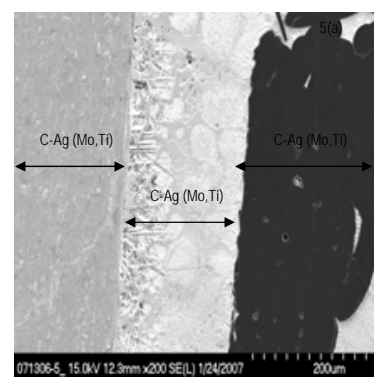

- Some dissolution of carbon in braze (possibly due to higher temperature of Ticusil).

- Carbon also detected within the Cu-clad-Mo region.

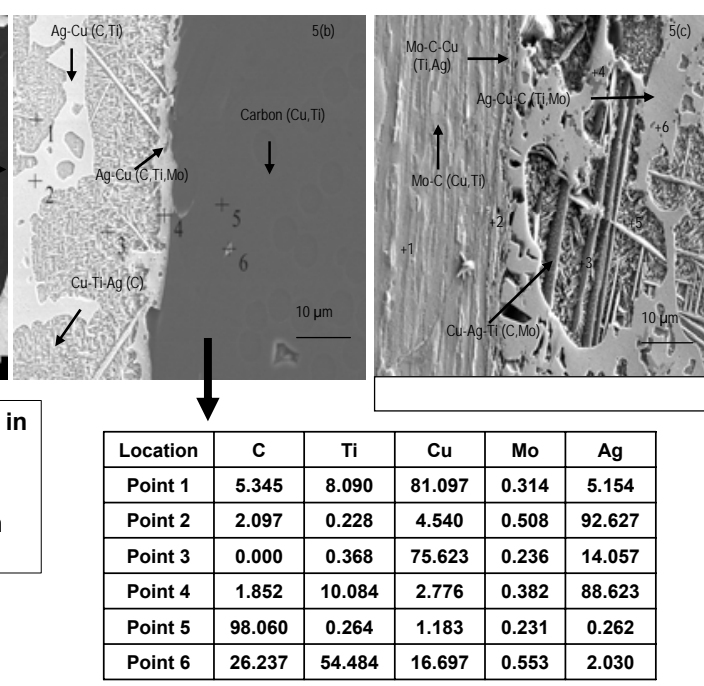

\section{C-C composite/Ticusil/Cu-clad-Mo joint} (resin-derived composite)
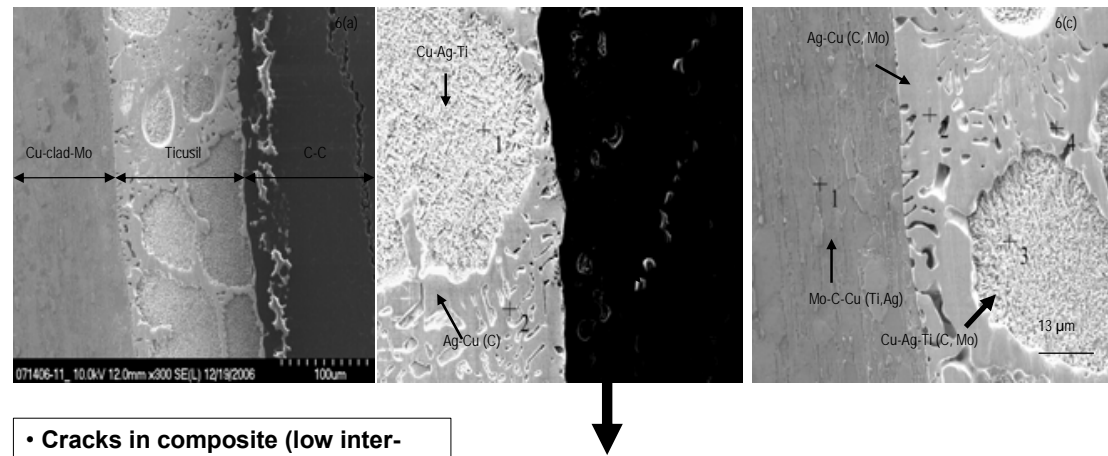

- Cracks in composite (low inter laminar shear strength).

- Braze displays eutectic structure with Ag- and $\mathrm{Cu}$-rich phases.

- Precipitation of Ag-rich phase on $\mathrm{C}-\mathrm{C}$ and $\mathrm{Cu}$-clad-Mo surfaces.

- A small amount of $\mathrm{Cu}$ detected within the $\mathrm{C}-\mathrm{C}$ composite.

\begin{tabular}{|c|c|c|c|c|c|}
\hline Location & $\mathrm{C}$ & $\mathrm{Ti}$ & $\mathrm{Cu}$ & $\mathrm{Mo}$ & $\mathrm{Ag}$ \\
\hline Point 1 & 0.799 & 6.603 & 77.559 & 0.422 & 14.617 \\
\hline Point 2 & 2.198 & 0.495 & 9.874 & 0.460 & 86.973 \\
\hline Point 3 & 99.472 & 0.112 & 0.000 & 0.198 & 0.218 \\
\hline Point 4 & 78.303 & 0.527 & 18.766 & 1.136 & 1.268 \\
\hline
\end{tabular}




\section{Knoop Hardness across Brazed Joints}

C-C (0).Ticusil.Cu-Clad-Mo

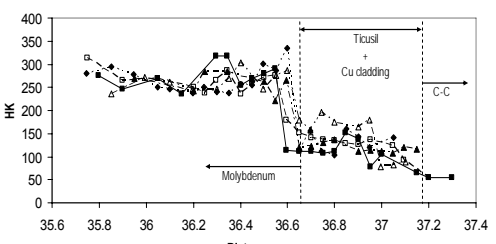

C-C (resin-derived).Ticusil.Cu-Clad-Mo

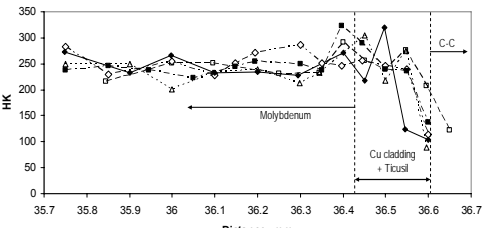

- No effect of fiber ply orientation and composite type (CVI vs resin-derived) on HK within the braze region.

- HK of Mo substrate is 200-330; HK depends on braze type: Ticusil (4.5\%Ti) has higher HK $(\sim 85-200)$ than Cusil-ABA (1.75\%Ti) ( 50-150).

- Some effect of larger residual stresses in Ticusil because of its higher joining temperature.

\section{Strain Energy in Brazed Joints}

Large strain energy $\rightarrow$ Greater tendency for fracture

(J.-W. Park, P. F. Mendez and T. W. Eagar, Acta Mater., 2002, 50(5), 883-899)

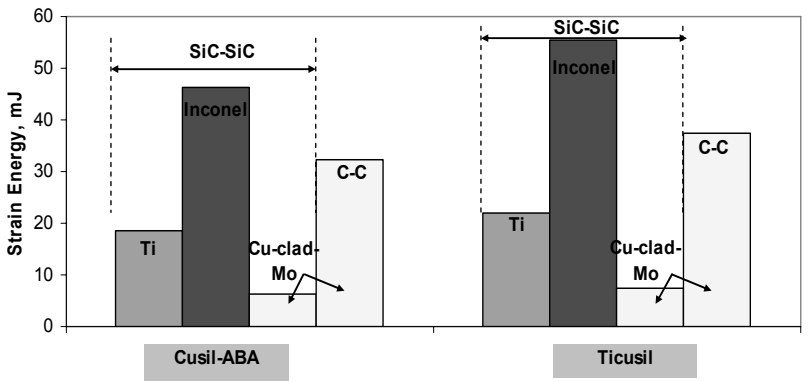

- Less strain energy develops in Cusil-ABA joints than in Ticusil joints.

- Strain energy C-C/Ticusil/Cu-clad-Mo joints is $\mathbf{3 7 . 5} \mathrm{mJ}$.

- Ductile braze and Cu cladding prevented failure.

- Lower strain energy in comparable joints of Cu-clad-Mo with SiC-SiC. 


\section{Estimation of Thermal Resistance in Brazed Joints \\ Effective thermal resistance (1-D steady-state conduction)}

$$
R_{\text {eff }}=\Sigma\left(\Delta \mathbf{x}_{\mathrm{i}} / \mathrm{K}_{\mathrm{i}}\right)
$$

$\left(\Delta \mathrm{x}_{\mathrm{i}}\right.$ : thickness $\mathrm{K}_{\mathrm{i}}$ : thermal conductivity)

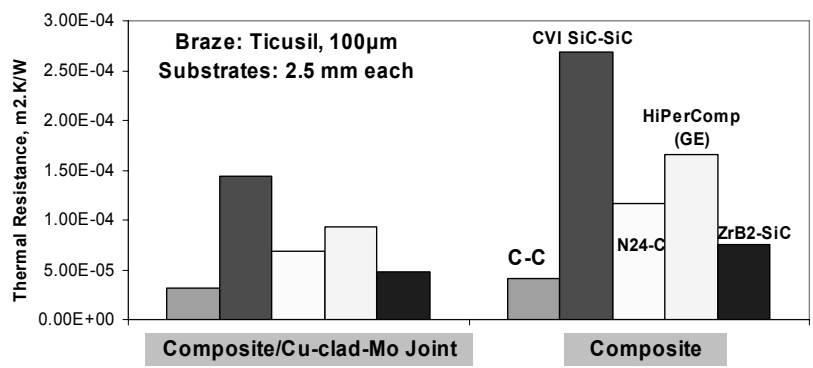

- C-C/Cu-clad-Mo joints have $22 \%$ lower thermal resistance than C-C.

- There is some weight penalty in joining $\mathrm{C}-\mathrm{C}$ to $\mathrm{Cu}$-clad-Mo $(39 \%$ increase in density).

- Potential benefit to join $\mathrm{C}-\mathrm{C}$ to $\mathrm{Cu}-\mathrm{clad}-\mathrm{Mo}$ in thermal management systems.

\section{Concluding Remarks}

- C-C composites with CVI and resin-derived matrices were brazed to Cu-clad-Mo using active braze alloys.

- SEM and EDS revealed sound bonding and Ti segregation at interface and no evidence of extensive chemical attack of C-C. There was limited redistribution of alloying elements.

- De-lamination in resin-derived C-C was observed due to its low inter-laminar shear strength (ILSS). Extensive braze infiltration of inter-fiber channels occurred in 3D composites.

- Sharp hardness gradients occurred at Cu-clad-Mo/braze interface. Ticusil exhibited greater hardness $(\sim 85-250 \mathrm{HK})$ than Cusil-ABA ( 50-150 HK). This may be due to higher Ti content of Ticusil (4.5\% Ti) than Cusil-ABA (1.75\% Ti).

- $\mathrm{C}$-C/Cu-clad-Mo joints may have $\sim 22 \%$ lower thermal resistance compared to $\mathrm{C}-\mathrm{C}$ composites. 
National Aeronautics and Space Administration

\section{Acknowledgement}

- Ceramics Branch, NASA Glenn Research Center, Cleveland, $\mathrm{OH}$ for support to R. Asthana.

www.nasa.gov 